\title{
Physical-Mechanical Properties of a Resin-Modified Calcium Silicate Material for Pulp Capping
}

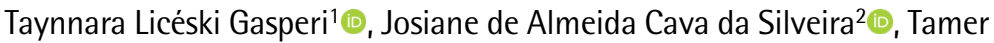
Ferreira Schmidt ${ }^{1} \mathbb{D}$, Cleonice da Silveira Teixeira ${ }^{1} \mathbb{D}$, Lucas da Fonseca Roberti Garcia $^{1}\left(\mathbb{D}\right.$, Eduardo Antunes Bortoluzzi $^{1}$ (D)

\begin{abstract}
The purpose of this study was to investigate and to compare the physical-mechanical
properties of a resin-modified calcium silicate material (TheraCal LC), used for pulp-
properties of a resin-modified calcium silicate material (TheraCal LC), used for pulpcapping, to MTA (Angelus) and a calcium hydroxide cement (Dycal). Specimens of each material $(n=12)$ were prepared in Teflon molds $(3.58 \mathrm{~mm} \times 3 \mathrm{~mm})$ and measured before and after immersion in distilled water for $24 \mathrm{~h}$ and 30 days to evaluate the dimensional change. The same specimens were submitted to compressive strength test on a Universal Testing Machine (Instron) ( $1 \mathrm{~mm} / \mathrm{min})$. Root canals were filled with the cements $(n=8)$, and after $24 \mathrm{~h}$, the bond strength (push-out test) to dentin was also assessed on a Universal Testing Machine (1 $\mathrm{mm} / \mathrm{min}$ ). Eight additional specimens of TheraCal LC were prepared to evaluate the bond strength immediately after light curing. Data were analyzed using One-Way ANOVA, and Tukey or Bonferroni post hoc tests $(p<0.05)$. Percentage expansion of TheraCal LC was above the Specification No. 57 of ANSI/ADA, in both periods. The dimensional change for TheraCal LC was higher than MTA in $24 \mathrm{~h}$ and 30 days; and Dycal in 30 days $(p<0.05)$. TheraCal $\mathrm{LC}$ had higher compressive and bond strength to dentin in comparison with MTA and Dycal $(p<0.05)$. Although TheraCal LC expanded more than the ANSI/ADA recommendation, its compressive and push-out bond strength to dentin were satisfactory and superior to MTA and Dycal.
\end{abstract}

'Department of Dentistry, Endodontics Division, Health Sciences Center, UFSC - Universidade Federal de Santa Catarina, Florianópolis, SC, Brazil ${ }^{2}$ School of Dentistry, Department of Endodontics, UNISUL Universidade do Sul de Santa Catarina, Palhoça, SC, Brazil

Correspondence: Dr. Lucas da Fonseca Roberti Garcia, Universidade Federal de Santa Catarina, Campus Reitor João David Ferreira Lima, Rua Roberto Sampaio Gonzaga, 274, 88040-900 Florianópolis, SC Brasil. Tel: +55-48-3721-5843. e-mail: drlucas.garcia@gmail.com

Key Words: calcium silicate cement; endodontics; physical properties; pulp capping.

\section{Introduction}

Pulpotomy is a widely used procedure in Pediatric Dentistry to preserve pulp vitality in primary teeth until the time of normal exfoliation (1). In cases of permanent teeth with incomplete root formation, it also plays a fundamental role, since the remaining vital pulp enables the complete formation of the root and supporting tissues (1). Calcium hydroxide-based materials, such as Dycal, have been indicated as the material of choice for pulp capping for several years because of their antimicrobial properties and for stimulating mineralized tissue formation $(2,3)$. However, despite these important features for maintaining pulp vitality, these materials have drawbacks, as porosity in the newly formed mineralized tissue barrier and solubility in tissue fluids (4). Nowadays, calcium hydroxide-based cements have been replaced by calcium silicate cements for pulp capping $(5,6)$. Calcium silicate cements, including the Mineral Trioxide Aggregate (MTA), produce calcium hydroxide as the main byproduct of its hydration (7), and for this reason have the same biological mechanism of action (8). MTA showed similar or better results than those of calcium hydroxide when used as pulp capping material (9). Nevertheless, MTA also exhibits some drawbacks as a capping material: long setting time, difficult handling, induction of tooth discoloration, and has no interaction with other materials placed on it $(7,9)$.

New calcium silicate cements have been developed trying to preserve the biological benefits of MTA, while improving its physical-mechanical characteristics. TheraCal $\mathrm{LC}$ (BISCO Inc.) is a new resin-modified, light-cured calcium silicate-based material to be used as a pulp capping agent and protective liner under restorative materials (10). In addition, to its easy handling characteristics and precise placement, TheraCal LC has shown good sealing ability, less interfacial microleakage, less solubility, and greater release of calcium ions in comparison with MTA and Dycal (10, 11). After light-curing (20 s per layer), TheraCal LC allows immediate placement of the final restorative material, since no delay is necessary as for other calcium silicate cements, being an attractive benefit $(10,11)$.

Due to the mentioned properties, TheraCal LC might be a better candidate for pulp capping than MTA and Dycal. Therefore, the purpose of this study was to evaluate certain physical-mechanical properties of TheraCal LC, required during pulp capping: dimensional change, compressive strength and push-out bond strength to dentin, in comparison with Angelus MTA and calcium hydroxide cement as controls. The hypothesis was that TheraCal LC is similar to the other materials considering the physicalmechanical properties evaluated. 


\section{Material and Methods}

\section{Cements}

The following cements described below were evaluated in the present study:

TheraCal LC (BISCO Inc., Schamburg, IL, USA): supplied by the manufacturer in pre-mixed syringes and requiring no preparation before use. The cement consists of a single paste containing calcium oxide, calcium silicate particles (type III Portland cement), strontium glass, fumed silica, barium sulphate, barium zirconate and resin containing bisphenol A-glycidyl methacrylate (Bis-GMA) and polyethylene glycol dimethacrylate (PEGDMA) (10).

MTA (Angelus Soluções Odontológicas, Londrina, PR, Brazil): mainly composed of white Portland cement and bismuth oxide (powder) and distilled water (liquid). Angelus MTA was prepared following the manufacturer's instructions by mixing at a 1:1 powder-to-liquid ratio.

Calcium hydroxide cement (Dycal, Dentsply Indústria e Comércio, Petrópolis, RJ, Brazil): self-setting radiopaque calcium hydroxide-based material, composed of a twopaste system - base paste (1,3-butylene glycol disalicylate, zinc oxide, calcium phosphate, calcium tungstate, iron oxide pigments) and - catalyst paste (calcium hydroxide, $\mathrm{N}$-ethyl-o/p-toluene sulphonamide, zinc oxide, titanium oxide, zinc stearate, iron oxide pigments). The cement was prepared following the manufacturer's instructions by mixing equal amounts of each paste.

\section{Dimensional Change after Setting}

For each cement, 24 cylindrical specimens were fabricated using Teflon molds (3.58-mm height $\times 3-\mathrm{mm}$ in diameter), according to the Carvalho-Junior et al. (12) methodology. After manipulation according to their respective manufacturers, the molds were filled with the cements, and after $5 \mathrm{~min}$, they were transferred to an oven at $37 \pm 1{ }^{\circ} \mathrm{C}$, with relative humidity of $95 \%$ for $24 \mathrm{~h}$. At the end of this period, the TheraCal specimens were lightcured for $20 \mathrm{~s}$ on both surfaces using a 1700- $\mathrm{mW} \mathrm{cm}-2$ LED lamp (TLED elca, Anthos, Italy) through a polyester strip (Directa Matrix Strips, Directa AB, Upplands, Väsby, Sweden), according to the manufacturer's instructions. The surface of the specimens of the tested cements were then polished with abrasive sandpaper \#600 (3M, São Paulo, SP, Brazil) under copious water cooling. Next, the specimens were removed from their molds and the length after setting (C) were measured with a digital caliper (Mitutoyo 7360, Suzano, SP, Brazil). Immediately after measurement, the specimens were individually placed in flasks containing 20 $\mathrm{mL}$ of distilled water and stored in an oven at $37 \pm 1{ }^{\circ} \mathrm{C}$ for $24 \mathrm{~h}$ or 30 days ( $\mathrm{n}=12$ for experimental period) (13). At the end of the experimental periods, the specimens were removed from the flasks, the excess of water was removed using an absorbent paper, and a new measurement of the length of the specimens was performed. The dimensional change was calculated using the following formula:

\section{$[(C F I N A L-C) / C] \times 100$}

where CFINAL = the length of the specimens throughout the experimental periods ( $24 \mathrm{~h}$ and 30 days), and $\mathrm{C}=$ the initial length of the specimen after setting. The dimensional change test was performed in triplicate.

\section{Compressive Strength}

Twelve specimens of each cement were fabricated for each experimental period ( $24 \mathrm{~h}$ and 30 days). The fabrication and dimensions of the specimens for the compressive strength test were identical to the specimens used in the dimensional change test.

After $24 \mathrm{~h}$ and 30 days, the specimens were removed from the molds and the excess of water was removed using an absorbent paper. The compressive strength was measured using a Universal Testing Machine (Instron Model 4444; Instron Corp., Canton, MA, USA) with a crosshead speed of $1 \mathrm{~mm} / \mathrm{min}$. The maximum load required for the fracture of each specimen was obtained and recorded. The compressive strength was calculated in MPa according to the following equation: $\mathrm{C}=4 \mathrm{P} / \pi \mathrm{D} 2$, where "P" represents the maximum load recorded by the machine in Newtons $(\mathrm{N})$, "D" is the specimen diameter in millimeters $(\mathrm{mm})$, and " $\mathrm{C}$ " is the maximum load in MPa (13).

\section{Push-Out Bond Strength}

After approval from the Research Ethics Committee (Protocol № 1.095.930), thirty-two single-rooted freshly extracted human teeth were selected for the bond strength test. The selected teeth had fully formed apices, only one straight root canal, no signs of fractures or cracks, no internal calcifications or carious lesions.

Initially, the crowns were sectioned using a double-sided diamond disc (KG Sorensen, Cotia, SP, Brazil) coupled to a low-speed rotation device (MRS 400; Dabi Atlante, Ribeirão Preto, SP, Brazil) below the cementoenamel junction under copious water cooling. The cervical third of the roots were sectioned transversally using a water-cooled low-speed ISOMET diamond saw (Buehler, Lake Bluff, IL, USA), in order to obtain two 2-mm-thick sections from each root. In each root section, the root canal was enlarged using burs No. 2 for fiber post preparation (Exacto, Angelus, Londrina, PR, Brazil) to obtain 1.6-mm diameter standardized cavities. The root sections were carefully examined in stereomicroscope (Discovery V12, Zeiss, Oberkochen, Germany), under 16x magnification. The specimens that presented cracks or defects were discarded from the final sample and replaced 
by new ones. Next, the root sections were immersed in 17\% EDTA for 3 min, followed by immersion in 1\% sodium hypochlorite solution for the same period. After, the specimens were immediately washed in distilled water and dried. The cavities were filled with the cements $(n=8)$ and stored at $37 \pm 1{ }^{\circ} \mathrm{C}$ for $24 \mathrm{~h}$. Eight additional specimens of TheraCal LC were fabricated and the bond strength was assessed immediately after light curing (group TheraCal light-cured). Then, the specimens were coupled to a metallic holder which was screwed to an aligning device holding it centered below a metallic piece with a cylindrical plunger. The aligning device was then fixed to the Universal Testing Machine (Instron Model 4444) and an apical compressive load was applied directly on the cement surface with a crosshead speed of $1 \mathrm{~mm} / \mathrm{min}$. The maximum load applied to the cement until displacement was recorded in Newtons (N). The push-out bond strength value in MPa was calculated from force $(\mathrm{N})$ divided by the area in $\mathrm{mm}^{2}\left(1 \mathrm{MPa}=1 \mathrm{~N} / \mathrm{mm}^{2}\right)$.

\section{Statistical Analysis}

Two-way analysis of variance (ANOVA) was performed to evaluate interactions amongst the two variables (type of cement and experimental period), and the post hoc $\therefore$ Bonferroni test was used for multiple comparisons, when dimensional change and compressive strength were evaluated. Data from the push-out bond strength test was analyzed by One-way ANOVA and Tukey's HDS post hoc test. Analyses were performed using SPSS software version 21.0 (SPSS Inc, Chicago, IL), and $\mathrm{P}$ values $<0.05$ were considered statistically significant.

\section{Results}

\section{Dimensional Change after Setting}

The mean values of dimensional change after setting are presented in Table 1. According to the Specification No.57 of ANSI/ADA (14), the mean linear shrinkage of a cement shall not exceed $1 \%$ or $0.1 \%$ in expansion. However, TheraCal LC presented expansion above the recommendation in both experimental periods, with significant difference between them (30 days and $24 \mathrm{~h})(\mathrm{p}<0.05)$. Although MTA has shown shrinkage at $24 \mathrm{~h}$ and expansion at the

Table 1. Mean values (\%) and standard deviation (SD) of the dimensional change for the different cements at $24 \mathrm{~h}$ and 30 days

\begin{tabular}{lccc}
\hline \multirow{2}{*}{ Period } & \multicolumn{3}{c}{ Dimensional change } \\
\cline { 2 - 4 } & Dycal & TheraCal LC & MTA \\
\hline $24 \mathrm{~h}$ & $0.38 \pm 0.83^{\mathrm{abA}}$ & $1.31 \pm 1.21^{\mathrm{aA}}$ & $-0.034 \pm 0.20^{\mathrm{bA}}$ \\
30 days & $-0.72 \pm 0.94^{\mathrm{aB}}$ & $3.89 \pm 1.7^{\mathrm{bB}}$ & $0.019 \pm 0.42^{\mathrm{aA}}$ \\
\hline
\end{tabular}

Different uppercase letters in columns (periods), and lowercase letters in lines (cements) mean statistically significant difference ( $p<0.05)$.
30 day-period, the mean value of dimensional change was similar between periods ( $p>0.05$ ). $0 n$ the other hand, Dycal had significantly difference between the $24 \mathrm{~h}$-period (expansion) and the 30 day-period (shrinkage) $(\mathrm{p}<0.05)$. However, both experimental periods were in accordance with the Specification No.57 of ANSI/ADA (14).

TheraCal LC and Dycal had similar dimensional change at $24 \mathrm{~h}$, characterized as expansion ( $p>0.05)$, different from the shrinkage of MTA ( $p<0.05)$. At the 30 day-period, TheraCal LC significantly expanded more than MTA and Dycal $(p<0.05)$.

\section{Compressive Strength}

The compressive strength values were statistically higher for TheraCal at $24 \mathrm{~h}$, when compared to the 30 day-period $(p<0.05)$. The opposite was observed for MTA. The compressive strength increased from $24 \mathrm{~h}$ to 30 days $(p<0.05)$. Similar compressive strength values were observed for Dycal at $24 \mathrm{~h}$ and 30 days ( $p>0.05)$. When the analysis was performed among cements in the same experimental period, TheraCal LC had significantly higher compressive strength than MTA and Dycal $(p<0.05)$ (Table 2).

\section{Push-Out Bond Strength}

The mean values of push-out bond strength for each cement are shown in Table 3. Similar bond strength values were observed between Dycal and MTA ( $p>0.05)$, and between TheraCal $\mathrm{LC}$ at the $24 \mathrm{~h}$ and TheraCal LC light-cured ( $p>0.05$ ). However, TheraCal LC at the $24 \mathrm{~h}$ and TheraCal $\mathrm{LC}$ light-cured had superior bond strength values to dentin in comparison with MTA and Dycal ( $p>0.05)$.

\section{Discussion}

Based on the results obtained in the present study, the hypothesis tested was rejected, since TheraCal LC presented, in general, superior physical-mechanical properties than MTA and Dycal. Because of the potential exposure to forces either upon the application of an overlying restorative material, or upon mastication, pulp capping materials are expected to provide good retention and adaptation to the dentin walls (15).

Table 2. Mean values (MPa) and standard deviation (SD) of the compressive strength for the different cements at $24 \mathrm{~h}$ and 30 days

\begin{tabular}{lccc}
\hline \multirow{2}{*}{ Period } & \multicolumn{3}{c}{ Compressive strength } \\
\cline { 2 - 4 } & Dycal & TheraCal LC & MTA \\
\hline $24 \mathrm{~h}$ & $17.16 \pm 3.80^{\mathrm{aA}}$ & $78.78 \pm 12.14^{\mathrm{bA}}$ & $37.92 \pm 6.64^{\mathrm{cA}}$ \\
30 days & $11.05 \pm 1.69^{\mathrm{aA}}$ & $69.06 \pm 12.97^{\mathrm{bB}}$ & $50.89 \pm 5.99^{\mathrm{cB}}$ \\
\hline
\end{tabular}

Different uppercase letters in columns (periods), and lowercase letters in lines (cements) mean statistically significant difference $(\mathrm{p}<0.05)$. 
Recently, new biomaterials, such as the light-cured resin-based cement TheraCal LC, have been produced to overcome the limitations of conventional MTA $(4,5)$. Due to its fluid consistency prior to light-curing, it is easier for the clinician to place it directly on the exposed pulp tissue (16). After, the material may be light-cured on demand, thereby, preventing its dissolution into the pulp tissue during a pulp capping procedure (16).

In the present study, MTA and Dycal were used as control materials to be compared to TheraCal LC, as both cements are the gold standard in pulp capping procedures (17), mainly due to their biocompatibility and proven bioactivity (2,3,7-9). Surprisingly, TheraCal LC expanded in both experimental periods higher than recommended by the Specification No. 57 of ANSI/ADA (14). At the 30 day-period, the expansion was more accentuated, and significantly higher than the MTA and Dycal values.

For this class of material, it would be expected shrinkage after light curing due to its resinous matrix (4). However, the hydration of TheraCal LC also depends on fluid uptake by the hydrophilic matrix $(10,21)$, and this hygroscopic alteration leads to expansion after the light curing (18). The hydrophilic monomers of TheraCal LC favor the water absorption, responsible for initiation of the hydration reaction of Portland cement particles $(10,21)$. The same phenomenon is observed for resin-modified glass ionomer cements, which have higher hygroscopic linear expansion than conventional glass ionomer cements, despite their resinous content (18). On the other hand, the unstable behavior of TheraCal LC in both experimental periods, with higher expansion than the recommendation of the Specification No. 57 of ANSI/ADA (14) should be positively correlated with the clinical conditions (19). The expansion of TheraCal LC might be a possible explanation to the superior sealing ability and less interfacial microleakage of this cement in comparison with Biodentine and MTA, as previously demonstrated (11).

It is also important to emphasize that the standard deviation in the Dycal and MTA groups were higher than the mean values of dimensional change (Table 1). However, this statistical finding might be considered irrelevant, as the dimensional change of these cements in both experimental

Table 3. Mean values (MPa) and standard deviation (SD) of the push-out bond strength for Dycal, TheraCal LC $24 \mathrm{~h}$, TheraCal LC light-cured and MTA

\begin{tabular}{cccc}
\hline Dycal & TheraCal 24 h & $\begin{array}{c}\text { TheraCal } \\
\text { light-cured }\end{array}$ & MTA \\
\hline $4.28 \pm 1.12^{\mathrm{a}}$ & $11.38 \pm 4.06^{\mathrm{b}}$ & $12.72 \pm 3.96^{\mathrm{b}}$ & $4.64 \pm 1.67^{\mathrm{a}}$ \\
\hline
\end{tabular}

Different lowercase letters in lines (cements) mean statistically significant difference $(\mathrm{p}<0.05)$. periods was in accordance with the Specification No. 57 of ANSI/ADA (14).

TheraCal LC had higher compressive strength than MTA and Dycal, in both experimental periods, corroborating the findings of Nielsen et al. (20). The authors reported that TheraCal LC had higher compressive strength at $15 \mathrm{~min}$, 3 and $24 \mathrm{~h}$ after light curing, when compared to MTA and Biodentine. The proper mechanical performance of TheraCal $\mathrm{LC}$ attests its potential to resist to fracture after immediate placement of a final restorative material on it during a pulp capping procedure (20).

The higher compressive strength of TheraCal LC may be related to its resinous nature $(10,21)$. Resin-based materials comprise an organic matrix of monomers and inorganic fillers, and their mechanical properties may range according to the composition, size, and content of the inorganic matrix $(10,21)$. TheraCal LC presents the most common organic matrix among resin-based materials, Bis-GMA (10), and an inorganic matrix containing different sizes of particles of barium, zirconium, silicon, strontium, aluminum and calcium (21). This complex microstructure is the responsible for providing the higher compressive strength of TheraCal LC when compared to conventional calcium silicate cements $(10,21)$, as reported in the present study.

The present study also showed higher push-out bond strength values for TheraCal LC in comparison with MTA and Dycal. To the best of our knowledge, there is no report on the literature about the push-out bond strength of TheraCal LC. Nonetheless, some studies evaluated the shear bond strength of TheraCal LC to resin composite $(15,22)$, and superior results to other calcium silicate cements were reported by these studies $(15,22)$.

Volumetric expansion of resin-based materials and cement penetration into the dentinal tubules may increase the bond strength between material and root canal walls (23). Higher bond strength values may also be related to the frictional resistance between dentin and cement (24). Furthermore, there is a chemical bond of TheraCal $\mathrm{LC}$ to dentin due to its ability in inducing the formation of hydroxyapatite-like crystals (21), which might increase the push-out bond strength of the cement.

The effective compressive strength and bond strength to dentin of TheraCal LC, observed in the present investigation, may support its use as a promising pulp capping material. It would be clinically beneficial for patients and professionals alike if the final restoration might be placed on the pulp capping material in the same visit, decreasing time and cost. However, caution should be taken regarding the biological properties of TheraCal LC, as the it has been linked to inflammatory effects on cells and less favorable pulpal responses (25). Therefore, from a biological point of view, incomplete clinical and experimental evidence 
demands further investigation to sustain its use as a pulp capping material.

Within the limitations of this in vitro study, it may be concluded that the expansion of TheraCal LC was higher than recommended by the Specification No.57 of ANSI/ ADA. Conversely, the compressive strength and the push-out bond strength to dentin were higher than MTA and Dycal. Considering its physical-mechanical properties, TheraCal LC may be considered a feasible option for pulp capping.

\section{Resumo}

0 objetivo deste estudo foi investigar e comparar as propriedades físicomecânicas de um material à base de silicato de cálcio modificado por resina (TheraCal LC) ao MTA (Angelus) e um cimento de hidróxido de cálcio (Dycal). Espécimes de cada material $(n=12)$ foram fabricados em moldes de Teflon (3,58 mm x $3 \mathrm{~mm}$ ) e medidos antes e após imersão em água destilada por $24 \mathrm{~h}$ e 30 dias para avaliar a alteração dimensional. Os mesmos espécimes foram submetidos ao teste de resistência à compressão em uma Máquina Universal de Testes (Instron) (1 mm/min). Canais radiculares foram preenchidos com os cimentos $(n=8)$, e após 24 $h$, a resistência de união (teste de push-out) também foi avaliada em uma Máquina Universal de Testes ( $1 \mathrm{~mm} / \mathrm{min}$ ). Oito amostras adicionais de TheraCal LC foram preparadas para avaliar a resistência de união imediatamente após a fotoativação. Os dados foram analisados utilizando os testes ANOVA de 1 -fator e Tukey; ou Bonferroni $(p<0,05)$. A expansão percentual do TheraCal LC ficou acima da Especificação No. 57 do ANSI/ ADA, em ambos os períodos. Os valores de alteração dimensional para TheraCal LC foram maiores que MTA em $24 \mathrm{~h}$ e 30 dias; e Dycal em 30 dias $(p<0,05)$. TheraCal $L C$ apresentou maior resistência à compressão e união à dentina em comparação ao MTA e Dycal $(p<0,05)$. Embora TheraCal LC tenha expandido mais que a recomendação da ANSI/ADA, sua resistência à compressão e de união à dentina foram satisfatórias e superiores ao MTA e Dycal.

\section{References}

1. Guideline on pulp therapy for primary and immature permanent teeth. American Academy of Pediatric Dentistry (AAPD) 2014;37:244-252.

2. Gandolfi $M G$, Siboni $F$, Botero $T$, Bossù $M$, Riccitiello $F$, Prati $C$. Calcium silicate and calcium hydroxide materials for pulp capping: biointeractivity, porosity, solubility and bioactivity of current formulations. J Appl Biomater Funct Mater 2015;13:43-60.

3. Taha NA, Khazali MA. Partial pulpotomy in mature permanent teeth with clinical signs indicative of irreversible pulpitis: a randomized clinical trial. J Endod 2017:43:1417-1421.

4. Bergenholtz G. Advances since the paper by Zander and Glass (1949) on the pursuit of healing methods for pulpal exposures: historical perspectives. Oral Surg Oral Med Oral Pathol Oral Radiol Endod 2005;100:S102-S108.

5. Smaïl-Faugeron V, Glenny AM, Courson F, Durieux P, Muller-Bolla M, Fron Chabouis H. Pulp treatment for extensive decay in primary teeth. Cochrane Database Syst Rev 2018;5:CD003220.

6. da Rosa WLO, Cocco AR, Silva TMD, Mesquita LC, Galarça AD, Silva AFD, et al. Current trends and future perspectives of dental pulp capping materials: A systematic review. J Biomed Mater Res B Appl Biomater 2018;106:1358-1368.

7. Camilleri J. Characterization and hydration kinetics of tricalcium silicate cement for use as a dental biomaterial. Dent Mater 2011;27:836-844.
8. Accorinte $M L$, Loguercio $A D$, Reis $A$, Carneiro $E$, Grande $R H$, Murata SS, Holland R. Response of human dental pulp capped with MTA and calcium hydroxide powder. Oper Dent 2008;33:488-495.

9. Parirokh $\mathrm{M}$, Torabinejad $\mathrm{M}$, Dummer PMH. Mineral trioxide aggregate and other bioactive endodontic cements: an updated overview - part I: vital pulp therapy. Int Endod J 2018;51:177-205.

10. Suh $B$, Cannon $M$, Yin $R$, Martin D. Polymerizable dental pulp healing capping, and lining material and method for use. International Patent A61K33/42; A61K33/42 Application number W02008US54387 20080220; Publication number W02008103712 (A2); Publication date June 28, 2008.

11. Makkar S, Kaur H, Anurag A, Vashisht R. A confocal laser scanning microscopic study evaluating the sealing ability of mineral trioxide aggregate, biodentine and a new pulp capping agent-theracal. Dent J Adv Stud 2016;3:19-25.

12. Carvalho-Junior JR, Correr-Sobrinho L, Correr AB, Sinhoreti MA, Consani $S$, Sousa-Neto MD. Solubility and dimensional change after setting of root canal sealers: a proposal for smaller dimensions of test samples. J Endod 2007;33:1110-1116.

13. ANSI/ADA: American National Standards Institute/American Dental Association. Specification no 96: Dental water-based cements; 1994.

14. ANSI/ADA: American National Standards Institute/American Dental Association. Specification n. 57 for Endodontic Sealing Materials; 2012.

15. Alzraikat H, Taha NA, Qasrawi D, Burrow MF. Shear bond strength of a novel light cured calcium silicate based-cement to resin composite using different adhesive systems. Dent Mater J 2016;35:881-887.

16. Bortoluzzi EA, Niu LN, Palani CD, El-Awady AR, Hammond BD, Pei DD, et al. Citotoxicity and osteogenic potential of silicate calcium cements as potential protective materials for pulpal revascularization. Dent Mater 2015;31:1510-1522.

17. Cai S, Zhang W, Tribble G, Chen W. Reactions of human dental pulp cells to capping agents in the presence or absence of bacterial exposure. J Oral Sci 2017;59:621-627.

18. Emamieh S, Gashemi A, Torabzadeh, H. Hygroscopic expansion of aesthetic restorative materials: one-year report. J Dent 2011;8:25-32.

19. Camps J, Pommel L, Bukiet F, About I. Influence of the powder/liquid ratio on the properties of zinc oxide-eugenol-based root canal sealers. Dent Mater 2004;20:915-923.

20. Nielsen MJ, Casey JA, VanderWeele RA, Vandewalle KS. Mechanical properties of new dental pulp-capping materials. Gen Dent 2016;64:44-48.

21. Camilleri, J. Hydration characteristics of Biodentine and Theracal used as pulp capping materials. Dent Mater 2014;30:709-715.

22. Meraji N, Camilleri J. Bonding over dentin replacement materials. J Endod 2017;43:1343-1349.

23. Ordinola-Zapata R, Bramante CM, Graeff MS, del Carpio Perochena A, Vivan RR, Camargo EJ, et al. Depth and percentage of penetration of endodontic sealers into dentinal tubules after root canal obturation using a lateral compaction technique: a confocal laser scanning microscopy study. Oral Surg Oral Med Oral Pathol Oral Radiol Endod 2009; 108:450-457.

24. Goracci C, Fabianelli A, Sadek FT, Papacchini F, Tay FR, Ferrari M. The contribution of friction to the dislocation resistance of bonded fiber posts. J Endod 2005;31:608-612.

25. Lee H, Shin Y, Kim SO, Lee HS, Choi HJ, Song JS. Comparative study of pulpal responses to pulpotomy with ProRoot MTA, RetroMTA, and Theracal in dogs' teeth. J Endod 2015;41:1317-1324.

Received November 30, 2019 Accepted January 23, 2020 